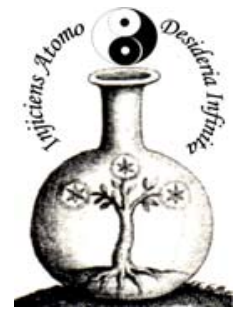

Special Issue

The Chemical Bond and Bonding

OPEN ACCESS

International Journal of

Molecular Sciences

ISSN 1422-0067

www.mdpi.com/journal/ijms

Communication

\title{
Anomalously Strong Effect of the Ion Sign on the Thermochemistry of Hydrogen Bonded Aqueous Clusters of Identical Chemical Composition
}

\author{
Alexey B. Nadykto ${ }^{1}{ }^{*}$, Fangqun $\mathrm{Yu}^{1}$ and Anas Al Natsheh ${ }^{2}$
}

1 Atmospheric Sciences Research Center, State University of New York at Albany, 251 Fuller Rd., Albany 12203, NY, USA

2 Kajaani University of Applied Sciences, Kuntokatu 5, 87101 Kajaani, Finland

* Author to whom correspondence should be addressed; E-Mail: alexn@asrc.cestm.albany.edu

Received: 23 May 2008; in revised form: 5 January 2009 / Accepted: 7 January 2009 / Published: 5 February 2009

\begin{abstract}
The sign preference of hydrogen bonded aqueous ionic clusters $X \pm\left(\mathrm{H}_{2} \mathrm{O}\right)_{i}$ (n $=1-5, X=\mathrm{F} ; \mathrm{Cl} ; \mathrm{Br}$ ) has been investigated using the Density Functional Theory and $a b$ initio MP2 method. The present study indicates the anomalously large difference in formation free energies between cations and anions of identical chemical composition. The effect of vibrational anharmonicity on stepwise Gibbs free energy changes has been investigated, and possible uncertainties associated with the harmonic treatment of vibrational spectra have been discussed.
\end{abstract}

Keywords: Ionic clusters, DFT, ab initio, sign preference, Gibbs free energies, hydrogen bonded complexes.

\section{Introduction}

The importance of a clear and insight understanding of ion-induced nucleation phenomena for a number of issues related to the Earth climate, air quality, public health and various technologies is well established [1-8]. Although the importance of the ion-induced nucleation became recognized long time ago, the pronounced ion sign effect on nucleation rates observed in Wilson's pioneering experiments 
[1] in the cloud chamber and known as a sign preference has remained a mystery up until now. Castleman and Tang [6] stated over 30 years ago that "understanding the effect of ions would be very difficult, or even impossible, if the ion's specific chemical characteristics had a significant effect on their nucleating efficiency". Recently, Nadykto et al. [5] pointed out that the strong effect of ion properties on nucleation rates is essentially quantum in nature, and is controlled by the electronic structure of the core ion through the influence on the intermolecular bonding energies during the initial steps of cluster formation. While core ions considered in [5] differ in both sign and chemical composition, species presented in this study differ in sign only. This allows separating the "sign" and "composition" effects and permits explicit treatment of the "pure" sign preference in aqueous systems. In the present Communication, the thermochemical properties of aqueous clusters $X^{ \pm}\left(H_{2} O\right)_{i}(\mathrm{n}=1-5, X$ $=\mathrm{F} ; \mathrm{Cl} ; \mathrm{Br}$ ) have been studied using the quantum theory at DFT-PW91PW91/6-311++G(3df,3pd) level. The main goals of the present Communication are to quantify the effect of the ion sign on the thermochemical properties of aqueous clusters of identical chemical composition and to estimate the effect of vibrational anharmonicity on the computed free energies.

\section{Methods}

Initial generated structures were treated initially by semi-empirical PM3 method and then by PW91PW91/6-31+G*. Finally, the most stable (within $\sim 4 \mathrm{kcal} /$ mole from the lowest energy isomer) structures obtained at PW91PW91/6-31+G* level have been optimized at PW91PW91/6$311++\mathrm{G}(3 \mathrm{df} .3 \mathrm{pd})$ level. PW91PW91/6-311++G(3df,3pd) has been used to obtain both equilibrium geometries and thermochemical properties from computed vibrational spectrums. The PW91PW91 density functional has been used in the combination with the largest Pople basis set 6$311++\mathrm{G}(3 \mathrm{df}, 3 \mathrm{pd})$ that provides quite small basis set superposition error (BSSE). In order to ensure the quality of the obtained DFT results, additional MP2/6-311++G(3df,3pd) calculations, both harmonic and anharmonic, have been carried out.

\section{Results and Discussion}

\subsection{Difference in Formation Free Energies Between Cations and Anions}

The interest to stepwise Gibbs free energy changes as standalone quantities is related directly to very high sensitivity of nucleation rates to the thermochemistry of initial cluster growth steps. Figure 1 presents the geometries of most stable isomers of $\mathrm{Cl}^{+}\left(\mathrm{H}_{2} \mathrm{O}\right)_{i}$ and $\mathrm{Cl}^{-}\left(\mathrm{H}_{2} \mathrm{O}\right)_{i}$. In addition to most stable isomers, a number of less stable conformers/local minima located within $\sim 5 \mathrm{kcal} \mathrm{mol}^{-1}$ of the most stable isomer/global minimum (1-5 for each $n$ ) have been identified for all the species $\mathrm{F}^{ \pm}\left(\mathrm{H}_{2} \mathrm{O}\right)_{i}$, $\mathrm{Cl}^{ \pm}\left(\mathrm{H}_{2} \mathrm{O}\right)_{i}$, and $\mathrm{Br}^{ \pm}\left(\mathrm{H}_{2} \mathrm{O}\right)_{i}$. Structures of clusters of the same ion sign $\mathrm{F}^{+}\left(\mathrm{H}_{2} \mathrm{O}\right)_{i}, \mathrm{Cl}^{+}\left(\mathrm{H}_{2} \mathrm{O}\right)_{i}$ and $\mathrm{Br}^{+}\left(\mathrm{H}_{2} \mathrm{O}\right)_{i}$, and $\mathrm{F}^{-}\left(\mathrm{H}_{2} \mathrm{O}\right)_{i}, \mathrm{Cl}^{-}\left(\mathrm{H}_{2} \mathrm{O}\right)_{i}$ and $\mathrm{Br}^{-}\left(\mathrm{H}_{2} \mathrm{O}\right)_{i}$ are similar, while structures of the clusters of the same composition and different sign are quite different. As may be seen from Figure 1, the water molecule in $\mathrm{Cl}^{-}\left(\mathrm{H}_{2} \mathrm{O}\right)_{i}$ is bonded to the core ion via $\mathrm{H}-\mathrm{Cl}$ bond, while that in $\mathrm{Cl}^{+}\left(\mathrm{H}_{2} \mathrm{O}\right)_{i}$ is bonded to the ions via the shorter $\mathrm{O}-\mathrm{Cl}$ bond. Similar pattern is observed in the case of $\mathrm{F}^{+}\left(\mathrm{H}_{2} \mathrm{O}\right)_{i}$, and $\mathrm{F}\left(\mathrm{H}_{2} \mathrm{O}\right)_{i}$, and $\mathrm{Br}^{+}\left(\mathrm{H}_{2} \mathrm{O}\right)_{i}$ and $\mathrm{Br}^{-}\left(\mathrm{H}_{2} \mathrm{O}\right)_{i}$. 
Figure 1. Structures and geometric properties of most stable isomers of $\mathrm{Cl}^{ \pm}\left(\mathrm{H}_{2} \mathrm{O}\right)_{i}$, (a) $\mathrm{Cl}^{-}$ $\left(\mathrm{H}_{2} \mathrm{O}\right)$; (b) $\mathrm{Cl}^{+}\left(\mathrm{H}_{2} \mathrm{O}\right)$; (c) $\mathrm{Cl}^{-}\left(\mathrm{H}_{2} \mathrm{O}\right)_{2}$; (d) $\mathrm{Cl}^{+}\left(\mathrm{H}_{2} \mathrm{O}\right)_{2}$; (e) $\mathrm{Cl}^{-}\left(\mathrm{H}_{2} \mathrm{O}\right)_{3}$; (f) $\mathrm{Cl}^{+}\left(\mathrm{H}_{2} \mathrm{O}\right)_{3} ;$; (g) $\mathrm{Cl}^{-}$ $\left(\mathrm{H}_{2} \mathrm{O}\right)_{4}$; (k) $\mathrm{Cl}^{+}\left(\mathrm{H}_{2} \mathrm{O}\right)_{4}$; (l) $\mathrm{Cl}^{-}\left(\mathrm{H}_{2} \mathrm{O}\right)_{5}$; (m) $\mathrm{Cl}^{+}\left(\mathrm{H}_{2} \mathrm{O}\right)_{5}$.

(a)

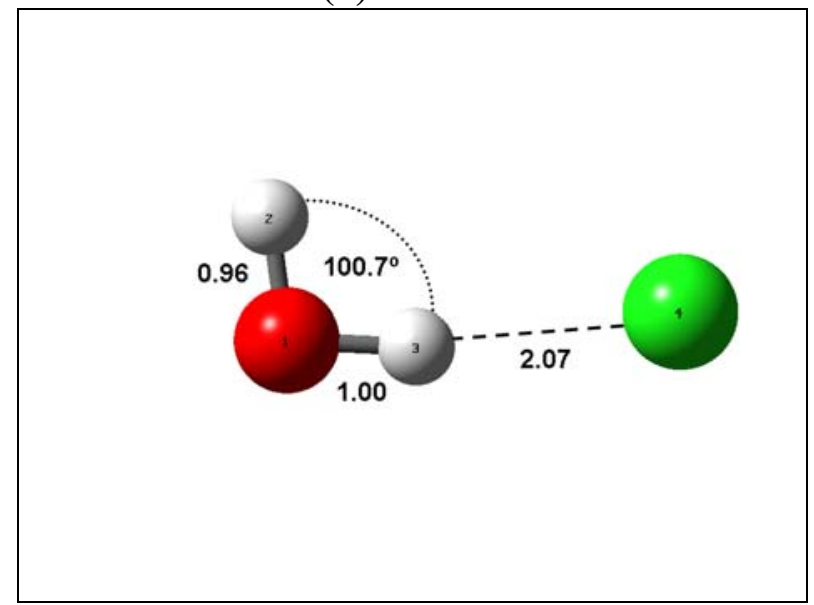

(c)

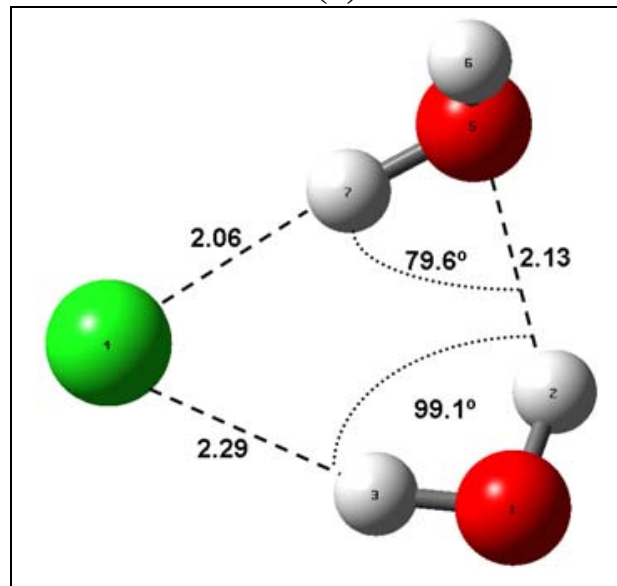

(e)

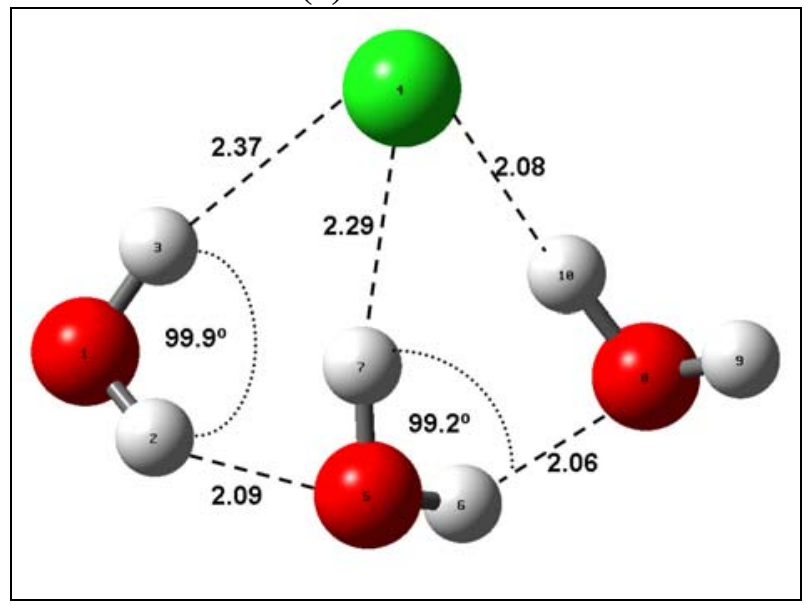

(b)

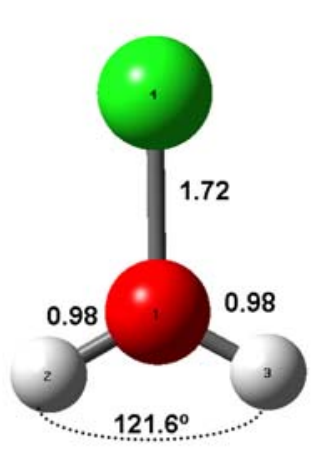

(d)

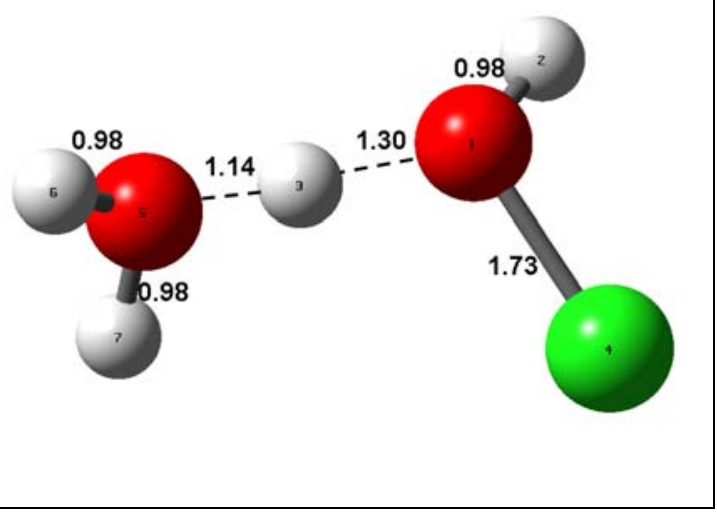

(f)

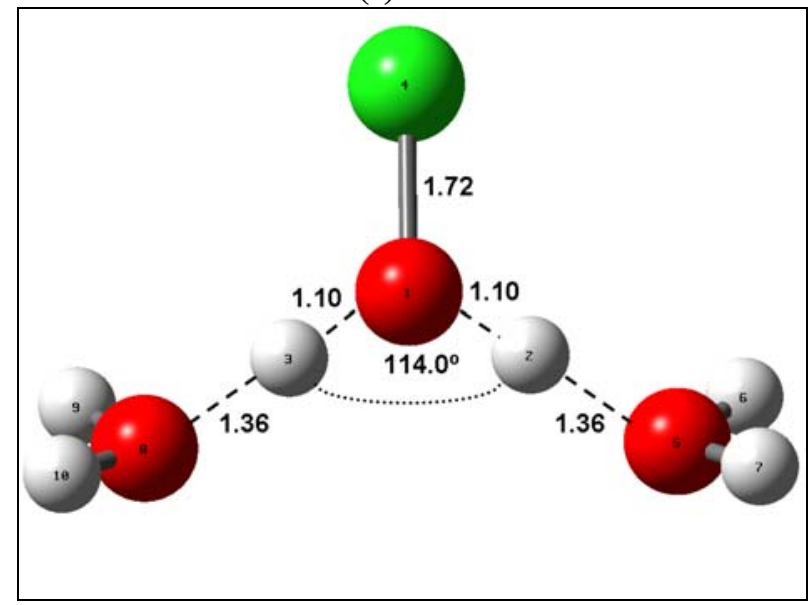


Figure 1. Cont.

(g)

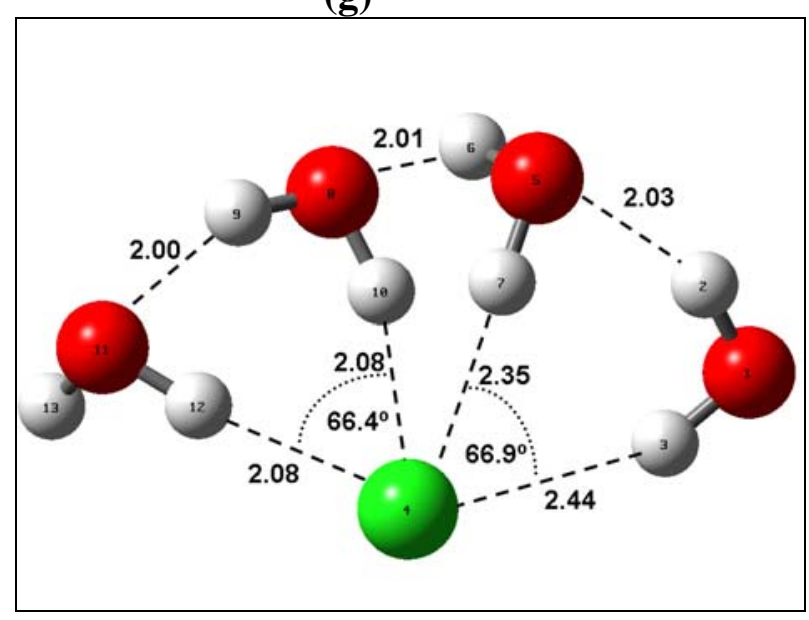

(1)

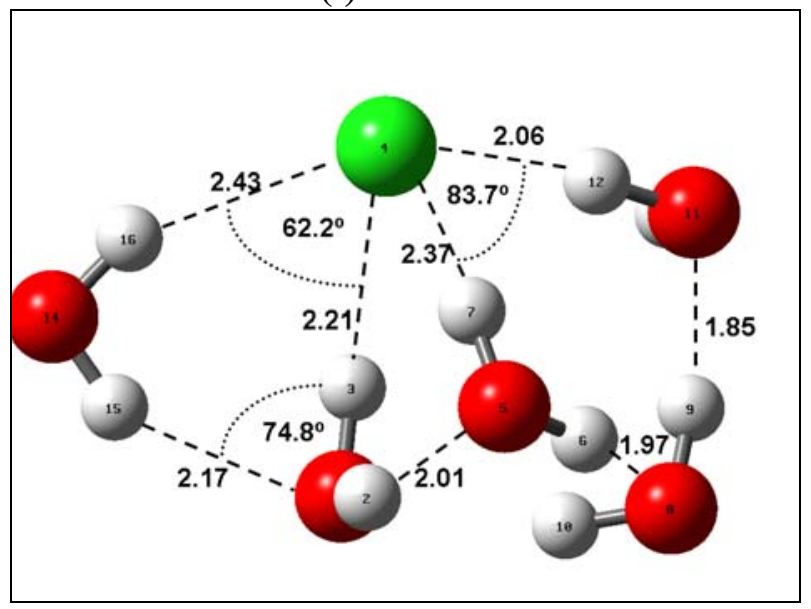

(k)

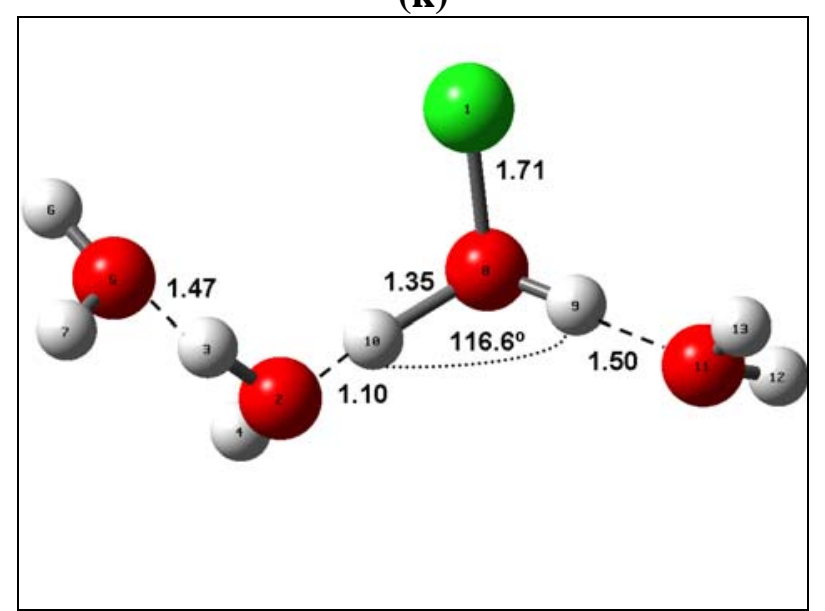

(m)

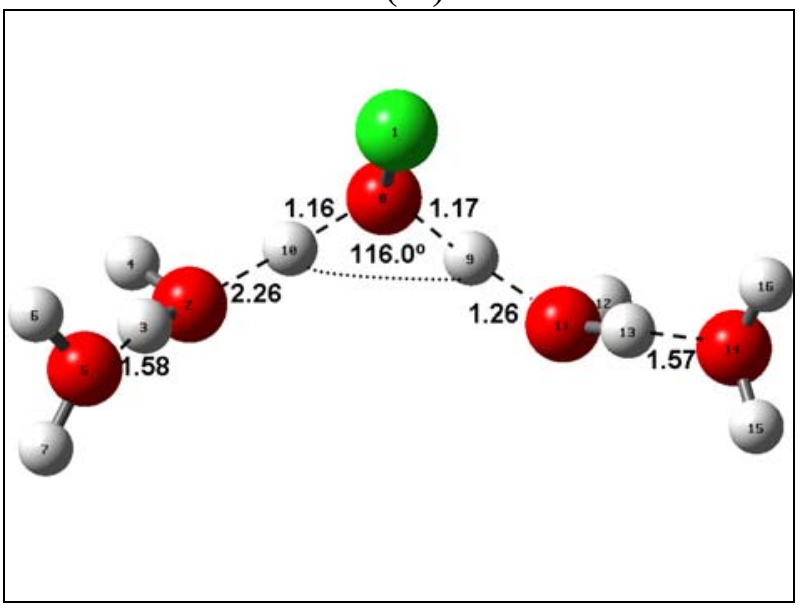

The difference in the cluster structure has direct impact on the stepwise Gibbs free energy changes associated with the addition of water molecules to the ionic clusters. Figure 2 presents the stepwise Gibbs free energies associated with $X^{ \pm}\left(\mathrm{H}_{2} \mathrm{O}\right)_{i-1}+\left(\mathrm{H}_{2} \mathrm{O}\right) \Leftrightarrow X^{ \pm}\left(\mathrm{H}_{2} \mathrm{O}\right)_{i}$ reaction.

As seen from Figure 2, cations have great growth advantage over anions. The difference in the Gibbs free energy is largely associated with the formation enthalpy and it decreases dramatically with the number of molecules in the clusters. The sign preference at the first growth steps is very strong, and the difference in the stepwise Gibbs free energy changes $\Delta G_{0,1}$ for $F^{ \pm}\left(\mathrm{H}_{2} \mathrm{O}\right)_{i}, \mathrm{Cl}^{ \pm}\left(\mathrm{H}_{2} \mathrm{O}\right)_{i}$ and $\mathrm{Br}^{ \pm}\left(\mathrm{H}_{2} \mathrm{O}\right)_{i}$ reaches $\sim 140,45$ and $65 \mathrm{kcal} \mathrm{mole}^{-1}$, respectively. This means that cations are much more efficient as nucleators of unary water vapours than anions of identical chemical composition. The stepwise changes in the Gibbs free energies correlate quit well with the mean ion sizes. For example, the hydration of the smallest ion $F^{+}\left(\mathrm{H}_{2} \mathrm{O}\right)$ of $0.149 \mathrm{~nm}$ in size (based on the volume calculation) is much stronger than that of bigger $\mathrm{Cl}^{-}\left(\mathrm{H}_{2} \mathrm{O}\right)(0.262 \mathrm{~nm}), \mathrm{Cl}^{+}\left(\mathrm{H}_{2} \mathrm{O}\right)(0.2 \mathrm{~nm}), \mathrm{Br}^{-}\left(\mathrm{H}_{2} \mathrm{O}\right)(0.283 \mathrm{~nm})$, $\mathrm{Br}^{+}\left(\mathrm{H}_{2} \mathrm{O}\right)(0.23 \mathrm{~nm})$ and $\mathrm{F}^{-}\left(\mathrm{H}_{2} \mathrm{O}\right)(0.194 \mathrm{~nm})$. 
Figure 2. Comparison of experimental and theoretical values of the stepwise Gibbs free energy change $\Delta G_{n-1, n}$ for $X^{ \pm}\left(\mathrm{H}_{2} \mathrm{O}\right)_{i-1}+\left(\mathrm{H}_{2} \mathrm{O}\right) \Leftrightarrow X^{ \pm}\left(\mathrm{H}_{2} \mathrm{O}\right)_{i}$ reactions (a, b, c), and the difference in the Gibbs free energy $\delta(j)$ between $j$-mers formed over core ions of opposite sign (d). Curves and symbols of refer to theoretical results and experimental data, respectively. Experimental data and theoretical data for $\mathrm{F}^{-}\left(\mathrm{H}_{2} \mathrm{O}\right)_{n}, \mathrm{Cl}^{-}\left(\mathrm{H}_{2} \mathrm{O}\right)$ and $\mathrm{Br}^{-}\left(\mathrm{H}_{2} \mathrm{O}\right)_{n}$, were adopted from [11], [5] and [10], respectively. The calculations were performed at the ambient temperature of $298.15 \mathrm{~K}$ and ambient pressure of $101.3 \mathrm{KPa}$.
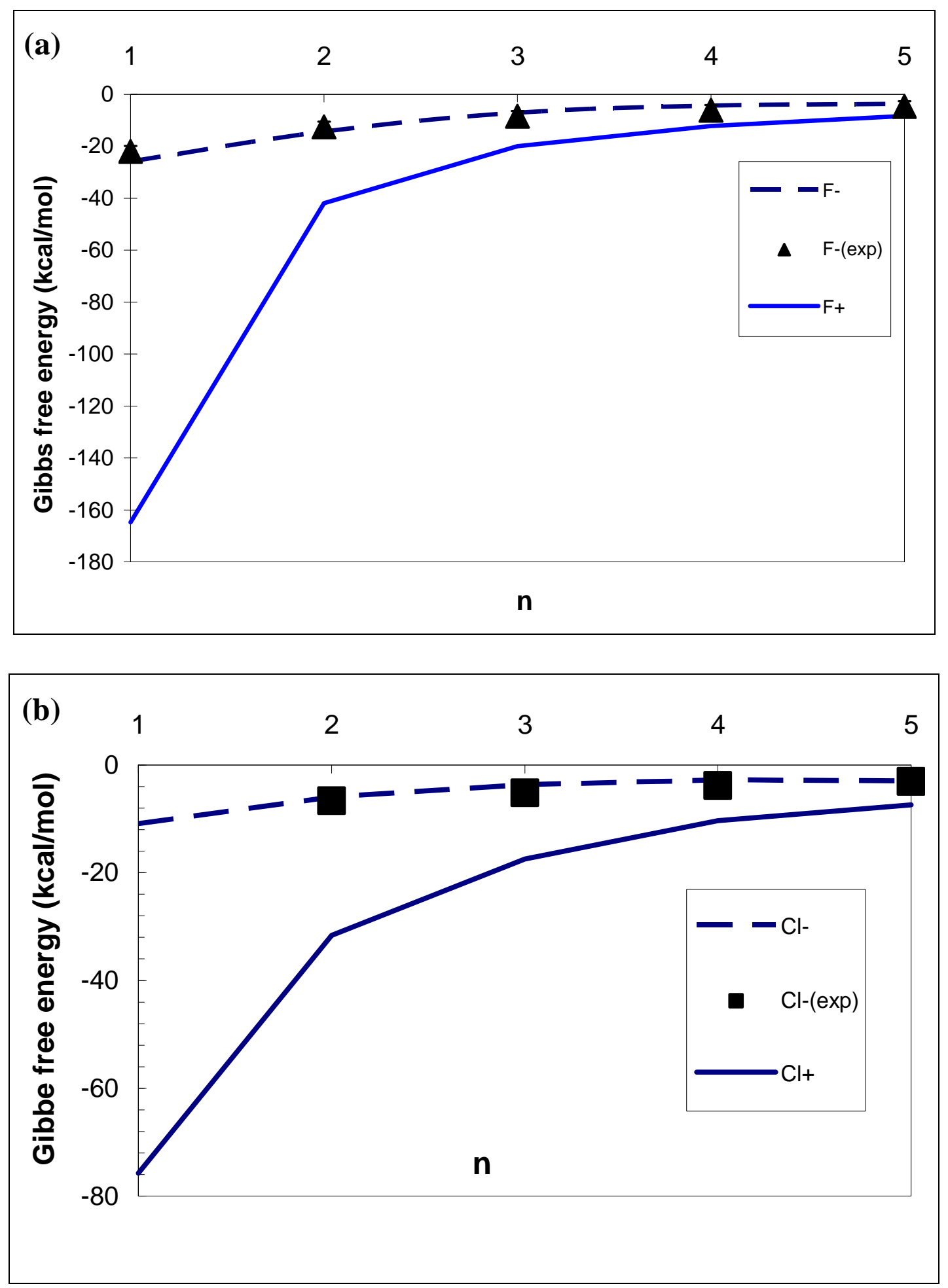
Figure 2. Cont.
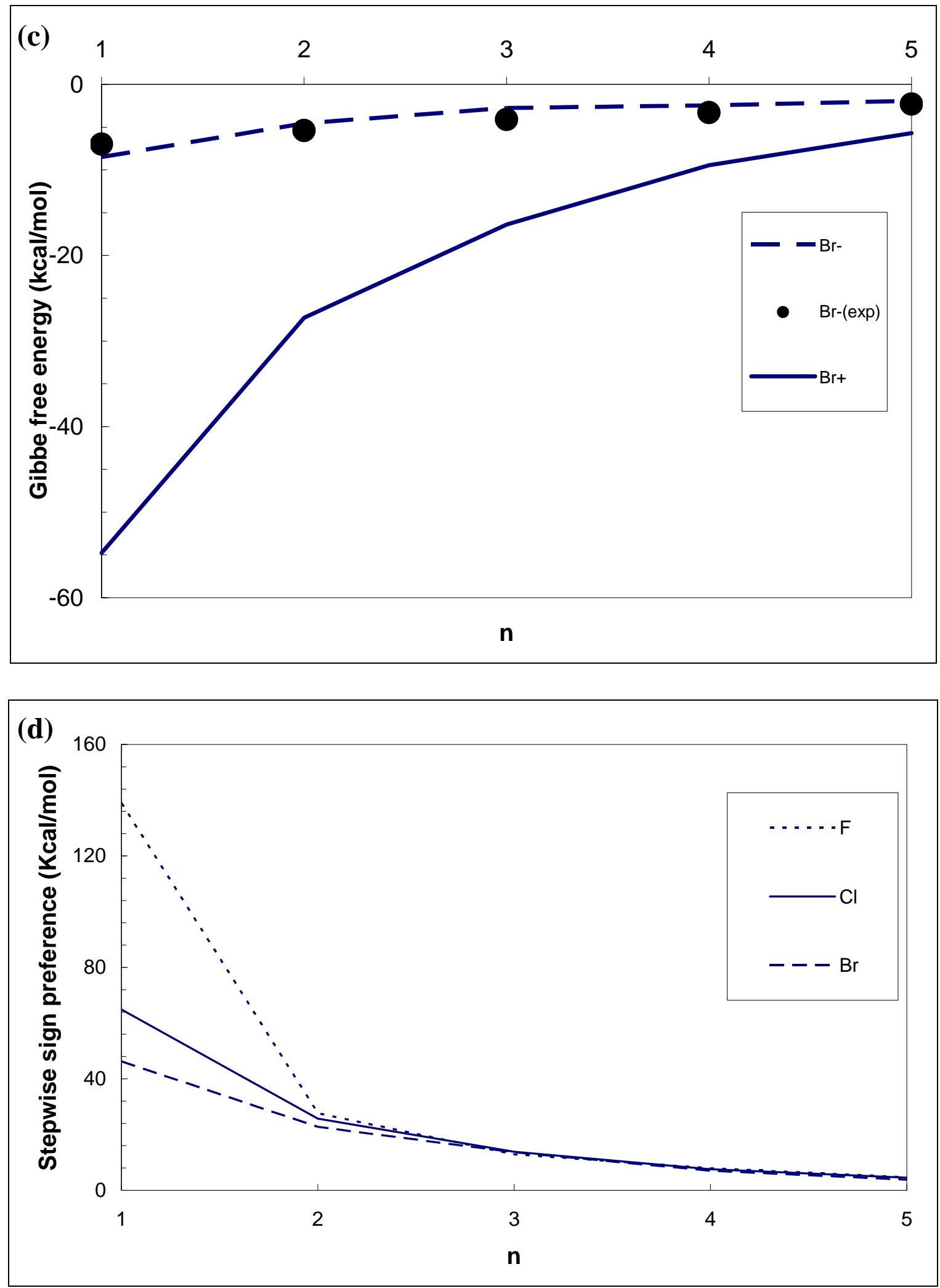

It is important to note that the sign preference of $\mathrm{Cl}^{ \pm}\left(\mathrm{H}_{2} \mathrm{O}\right)_{n}$ obtained in molecular-based studies using empirical interaction potential (TI4P) has a different sign. Moreover, the difference between quantum results and Monte-Carlo model predictions using empirical TIP4P water model is excessively large. While the Monte Carlo model [12-13] predicts the thermochemistry of $\mathrm{Cl}^{-}\left(\mathrm{H}_{2} \mathrm{O}\right)_{n}$ in a good 
agreement with the present results and experimental data, its deviation in Gibbs free energy for $\mathrm{Cl}^{+}\left(\mathrm{H}_{2} \mathrm{O}\right)_{n}[13]$ from the present study exceeds several tens of kcal mole ${ }^{-1}$.

\subsection{Vibrational Anharmonicity}

Ongoing discussion [7-8] about the validity of the commonly used harmonic approximation motivated us to perform additional analysis of harmonic and anharmonic cluster spectra and validate them against available experimental data. Tables 1, 2 and 3 present the comparison of the theoretical PW91PW91/6-311++G(3df,3pd) and MP2/6-311++G(3df,3pd) results obtained using the harmonic approximation with anharmonic results and experimental data.

Table 1. Experimental and theoretical frequencies of $F\left(H_{2} O\right)\left(\mathrm{cm}^{-1}\right)$. Subscripts $\mathrm{H}$ and A refer to harmonic and anharmonic calculations, respectively.

\begin{tabular}{|c|c|c|c|c|c|c|c|c|c|}
\hline & \multicolumn{6}{|c|}{$\mathrm{F}^{-}\left(\mathrm{H}_{2} \mathrm{O}\right)$} & \multicolumn{3}{|c|}{$\mathrm{F}^{-}\left(\mathrm{H}_{2} \mathbf{O}\right)_{2}$} \\
\hline & PW91 $^{\mathrm{H}}$ & PW91 ${ }^{A}$ & MP2 $^{\mathrm{H}}$ & $\mathbf{M P 2}^{\mathrm{A}}$ & $\operatorname{Exp}^{a}$ & $\operatorname{Exp}^{b}$ & PW91 $^{\mathrm{H}}$ & PW91 ${ }^{A}$ & $\operatorname{Exp}^{a}$ \\
\hline 1 & 3768 & 3556 & 3952 & 3770 & 3690 & 3687 & 3776 & 3578 & 3700 \\
\hline 2 & 1844 & 1783 & 2069 & 953 & & & & & \\
\hline 3 & 1623 & 1609 & 1715 & 1625 & & 1650 & 2717 & 2375 & 2520 \\
\hline 4 & 1157 & 1178 & 1242 & 1260 & & $1083-1250$ & 2506 & 2236 & 2435 \\
\hline 5 & 569 & 598 & 595 & 586 & & & & & \\
\hline 6 & 436 & 401 & 412 & 441 & & & & & \\
\hline
\end{tabular}

Table 2. Experimental and theoretical frequencies of $\mathrm{Cl}^{-}\left(\mathrm{H}_{2} \mathrm{O}\right)\left(\mathrm{cm}^{-1}\right)$. Subscripts $\mathrm{H}$ and A refer to harmonic and anharmonic calculations, respectively.

\begin{tabular}{|c|c|c|c|c|c|c|c|c|c|}
\hline & \multicolumn{5}{|c|}{$\mathrm{Cl}^{-}(\mathrm{H} 2 \mathrm{O})$} & \multicolumn{4}{|c|}{$\mathrm{Cl}^{-}\left(\mathrm{H}_{2} \mathrm{O}\right)_{2}$} \\
\hline & PW91 $^{\mathrm{H}}$ & PW91 $^{\mathrm{H}}$ & $\mathrm{MP}^{\mathrm{H}}$ & MP2 $^{\mathrm{A}}$ & Exp. & PW91 $^{\mathrm{H}}$ & PW91 $^{\mathrm{A}}$ & exp.1 & $\exp .2$ \\
\hline 1 & 3770 & 3567 & 3952 & 3764 & $3698^{\mathrm{a}}, 3690^{\mathrm{a}}, 3699^{\mathrm{c}}$ & & & & \\
\hline 2 & 3069 & 2740 & 3376 & 3161 & $3285^{\mathrm{a}}, 3130^{\mathrm{a}}, 3130^{\mathrm{c}}$ & 3618 & 3431 & $3700^{\mathrm{a}}$ & $3686^{\mathrm{a}}$ \\
\hline 3 & 1626 & 1612 & 1678 & 1743 & $1650^{\mathrm{b}}$ & 3418 & 3092 & $3317^{\mathrm{a}}$ & $3375^{\mathrm{a}}$ \\
\hline 4 & 763 & 782 & 794 & 795 & $745^{\mathrm{c}}$ & 3037 & 2720 & $3245^{\mathrm{a}}$ & $3130^{\mathrm{a}}$ \\
\hline 5 & 394 & 352 & 387 & 366 & & & & & \\
\hline 6 & 215 & 204 & 200 & 196 & $210^{\mathrm{a}}, 155^{\mathrm{a}}$ & & & & \\
\hline
\end{tabular}

${ }^{\mathrm{a}}$ [15] compilation of experimental data; ${ }^{\mathrm{b}}[16]$ compilation of experimental data; ${ }^{\mathrm{c}}[17]$. 
Table 3. Experimental and theoretical frequencies of $\mathrm{Br}^{-}\left(\mathrm{H}_{2} \mathrm{O}\right)\left(\mathrm{cm}^{-1}\right)$. Subscripts $\mathrm{H}$ and A refer to harmonic and anharmonic calculations, respectively.

\begin{tabular}{|c|c|c|c|c|c|}
\hline & PW91 $^{\mathbf{H}}$ & PW91 $^{\mathbf{A}}$ & $\mathbf{M P 2}^{\mathbf{H}}$ & $\mathbf{M P 2}^{\mathbf{A}}$ & $\mathbf{E x p}^{\mathbf{a}}$ \\
\hline 1 & 3769 & 3575 & 3948 & 3759 & 3689 \\
2 & 3223 & 2871 & 3506 & 3257 & 3270 \\
3 & 1619 & 1578 & 1669 & 1633 & 1642 \\
4 & 668 & 675 & 699 & 690 & 664 \\
5 & 323 & 345 & 328 & 310 & \\
6 & 161 & 159 & 158 & 155 & 158 \\
\hline \multicolumn{5}{|c}{${ }^{a}[17]$}
\end{tabular}

Figure 3. Ratio of anharmonic ZPE to harmonic ZPE.

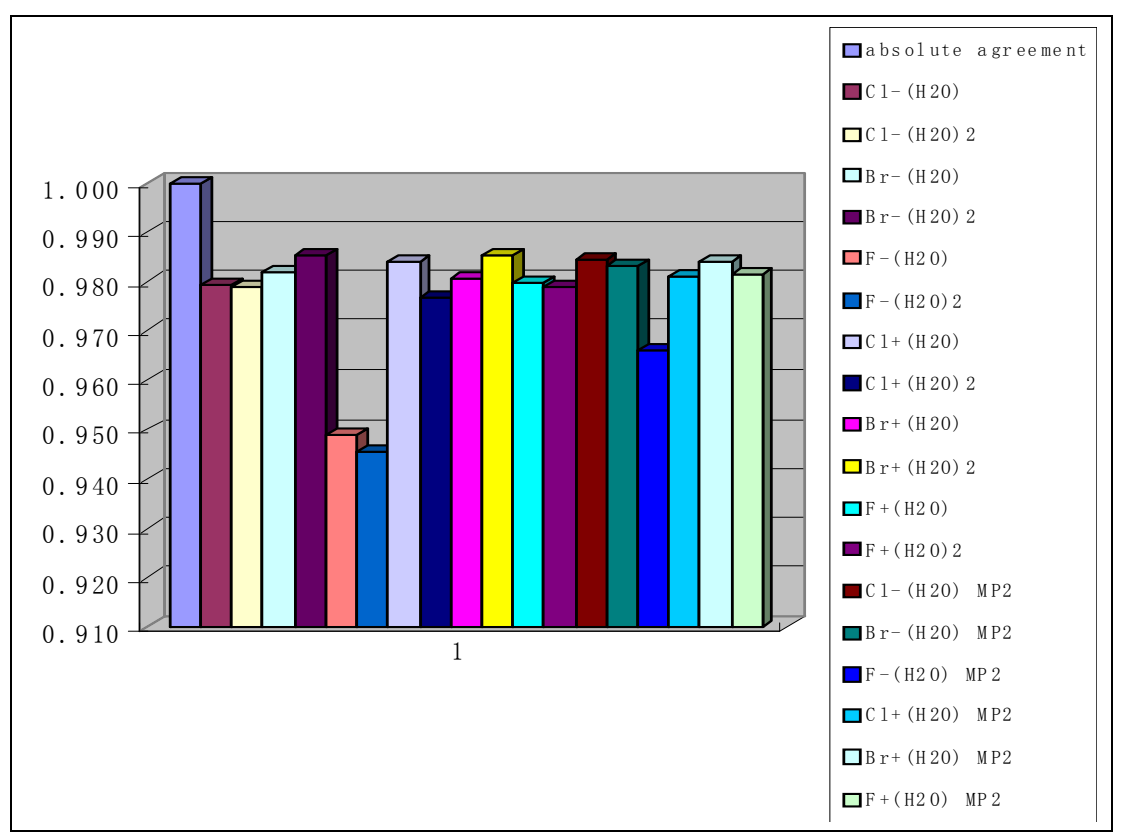

Table 4. Ratio of anharmonic ZPE to harmonic ZPE.

\begin{tabular}{|c|c|c|c|}
\hline $\mathrm{Cl}^{-}\left(\mathrm{H}_{2} \mathrm{O}\right)$ & 0.979 & $\mathrm{Cl}^{-}\left(\mathrm{H}_{2} \mathrm{O}\right) \mathrm{MP} 2$ & 0.985 \\
$\mathrm{Cl}^{-}(\mathrm{H} 2 \mathrm{O})_{2}$ & 0.979 & & \\
$\mathrm{Br}^{-}\left(\mathrm{H}_{2} \mathrm{O}\right)$ & 0.982 & $\mathrm{Br}^{-}\left(\mathrm{H}_{2} \mathrm{O}\right) \mathrm{MP} 2$ & 0.983 \\
$\mathrm{Br}^{-}\left(\mathrm{H}_{2} \mathrm{O}\right)_{2}$ & 0.985 & & \\
$\mathrm{~F}^{-}\left(\mathrm{H}_{2} \mathrm{O}\right)$ & 0.949 & $\mathrm{~F}^{-}\left(\mathrm{H}_{2} \mathrm{O}\right) \mathrm{MP} 2$ & 0.966 \\
$\mathrm{~F}^{-}\left(\mathrm{H}_{2} \mathrm{O}\right)_{2}$ & 0.945 & & \\
$\mathrm{Cl}^{+}\left(\mathrm{H}_{2} \mathrm{O}\right)$ & 0.984 & $\mathrm{Cl}^{+}\left(\mathrm{H}_{2} \mathrm{O}\right) \mathrm{MP} 2$ & 0.981 \\
$\mathrm{Cl}^{+}\left(\mathrm{H}_{2} \mathrm{O}\right)_{2}$ & 0.977 & & \\
$\mathrm{Br}^{+}\left(\mathrm{H}_{2} \mathrm{O}\right)$ & 0.981 & $\mathrm{Br}^{+}\left(\mathrm{H}_{2} \mathrm{O}\right) \mathrm{MP} 2$ & 0.984 \\
$\mathrm{Br}^{+}\left(\mathrm{H}_{2} \mathrm{O}\right)_{2}$ & 0.985 & & \\
$\mathrm{~F}^{+}\left(\mathrm{H}_{2} \mathrm{O}\right)$ & 0.980 & $\mathrm{~F}^{+}\left(\mathrm{H}_{2} \mathrm{O}\right) \mathrm{MP} 2$ & 0.981 \\
$\mathrm{~F}+\left(\mathrm{H}_{2} \mathrm{O}\right)_{2}$ & 0.979 & \multicolumn{2}{|l}{} \\
\hline \multicolumn{2}{|l}{}
\end{tabular}


Tables 1, 2 and 3 show clearly that the performance of the harmonic approximation implemented in the framework of the PW91PW91/6-311++G(3df,3pd) method is well beyond satisfactory in all the cases studied here. It is important to note that the application of the anharmonic correction [19] does not lead to any substantial improvement in the theoretical predictions.

Another important indication of the reasonable performance of the harmonic approximation implemented in the frame of DFT PW91PW91/6-311++G(3df,3pd) method has been obtained from the comparison of Zero Point Energies (ZPE) computed using the harmonic and anharmonic approximation. As seen from Figure 3 and Table 4, the difference between the harmonic and anharmonic ZPE typically does not exceed 2-3\%. This finding is in excellent agreement with the recent MP2 study [14] of pure water clusters. Another important detail is that DFT results are in good agreement with ab initio MP2 predictions. The contribution of the vibrational anharmonicity to the computed Gibbs free energies does not exceed 0.03-0.2 $\mathrm{kcal} \mathrm{mol}^{-1}$. This leads us to conclude that anharmonicity is unlikely a source of large uncertainties in the computed Gibbs free energies in all the cases studied here.

\section{Conclusions}

The present study leads us to the following conclusions:

(a) The effect of ion sign on the formation free energies of aqueous ionic clusters of identical chemical composition is very strong. For example, the difference in the stepwise Gibbs free energy changes $\Delta G_{0,1}$ for $F^{ \pm}\left(\mathrm{H}_{2} \mathrm{O}\right)_{i}, \mathrm{Cl}^{ \pm}\left(\mathrm{H}_{2} \mathrm{O}\right)_{i}$ and $\mathrm{Br}^{ \pm}\left(\mathrm{H}_{2} \mathrm{O}\right)_{i}$ reaches $\sim 140,65$ and $45 \mathrm{kcal}$ mole $^{-1}$, respectively. It is important to note that the positive sign preference found for unary water vapours does not contradict with the opposite (negative) sign preference observed in recent experiments in binary sulfuric acid-water vapours [20-22]. In contrast to unary clusters, whose stability is controlled by the affinity of water monomers to ions, the stability of more complex binary clusters studied by Froyd and Lovejoy [20,21] and Sorokin et al. [22] is controlled by two somewhat competing factors : affinities of $\mathrm{H}_{2} \mathrm{O}$ and $\mathrm{H}_{2} \mathrm{SO}_{4}$ to the ions. While the affinity of water to cations is stronger than that to anions, the affinity of $\mathrm{H}_{2} \mathrm{SO}_{4}$, the key binary nucleation precursor, to ions exhibits the opposite behavior. This leads, due to the very large difference in the affinity of $\mathrm{H}_{2} \mathrm{SO}_{4}$ between anions and cations, to the negative sign preference observed in the experiments [23].

(b) The harmonic approximation implemented in the framework of the DFT works well in the case of aqueous ionic clusters. Both DFT and ab initio MP2 studies show that the effect of vibrational anharmonicity is mild, and is unlikely a source of large uncertainties in computed free energies.

\section{Acknowledgements}

Support of this work by the U.S. National Science Foundation under grant 0618124 is gratefully acknowledged. 


\section{References}

1. Wilson, C.T.R. Condensation of water vapour in the presence of dust-free air and other gases. Phil. Trans. R. Soc. London A 1897, 189, 265-307.

2. Yu, F.; Turco, R.P. From molecular clusters to nanoparticles: The role of ambient ionization in tropospheric aerosol formation. Geophys. Res. Lett. 2000, 27, 883-887.

3. Lee, S.-H.; Reeves, J.M.; Wilson, J.C.; Hunton, D.E.; Viggiano, A.A.; Miller, T.M.; Ballenthin, J.O.; Lait, L.R. Particle formation by ion nucleation in the upper troposphere and lower stratosphere. Science 2003, 301, 1886-1889.

4. Nadykto, A.B.; Yu. F. Dipole of condensing monomers: A new parameter controlling ion-induced nucleation. Phys. Rev. Lett. 2004, 93, 016101-016104.

5. Nadykto, A.B.; Al Natsheh, A.; Yu, F.; Mikkelsen, K.V.; Russkanen, J. Qunatum nature of the sign preference in ion-induced nucleation. Phys. Rev. Lett. 2006, 96, 125701-125704.

6. Castleman, A.W., Jr.; Tang, I. N. Role of small clusters in nucleation about ions. J. Chem. Phys. 1972, 57, 3629-3638.

7. Kathmann, S.M.; Schenter, G.K.; Garrett, B.C. Comment. Phys. Rev. Lett. 2007, 98, 109603

8. Nadykto, A. B.; Al Natsheh, A.; Yu, F.; Mikkelsen, K.V.; Russkanen, J. Reply Comment. Phys. Rev. Lett. 2007, 98, 109604.

9. Frisch, M.J.; Trucks, G.W.; Schlegel, H.B.; Scuseria, G.E.; Robb, M.A.; Cheeseman, J.R.; Montgomery, J.A., Jr.; Vreven, T.; Kudin, K.N.; Burant, J.C.; et al. Gaussian 03, Gaussian. Inc., Walingford, CT, 2004.

10. Arshadi, M.; Yamdagni, R.; Kebarle, P. Hydration of halide negative ions in the gas phase. II. Comparison of hydration energies for the alkali positive and halide negative ions. J. Phys. Chem. 1970, 74, 1475-1489.

11. Hiraoka, K.; Mizuse, S.; Yamabe, S. Solvation of halide ions with $\mathrm{H}_{2} \mathrm{O}$ and $\mathrm{CH}_{3} \mathrm{CN}$ in the gas phase. J. Phys. Chem. 1988, 92, 3943 -3957.

12. Kathmann, S.M.; Schenter, G.K.; Garrett, B.C. The critical role of anharmonicity in aqueous ionic clusters relevant to nucleation. J. Phys. Chem. C 2007, 111, 4977-4983.

13. Kathmann, S.M.; Schenter, G.K.; Garrett, B.C. Ion-induced nucleation: The importance of chemistry. Phys. Rev. Lett. 2005, 94, 116104-116107.

14. Diri, K.; Myshakin, E.M.; Jordan, K.D. On the contribution of vibrational anharmonicity to the binding energies of water clusters. J. Phys. Chem. A 2005, 109, 4005-4009.

15. Chaban, G.M.; Jung, J.O.; Gerber, R.B. Anharmonic vibrational spectroscopy of hydrogenbonded systems directly computed from ab initio potential surfaces: $\left(\mathrm{H}_{2} \mathrm{O}\right)_{\mathrm{n}}, \mathrm{n}=2,3 ; \mathrm{Cl}^{-}\left(\mathrm{H}_{2} \mathrm{O}\right)_{\mathrm{n}}, \mathrm{n}$ $=1,2 ; \mathrm{H}^{+}\left(\mathrm{H}_{2} \mathrm{O}\right)_{\mathrm{n}}, \mathrm{n}=1,2 ; \mathrm{H}_{2} \mathrm{O}-\mathrm{CH}_{3} \mathrm{OH}$. J. Phys. Chem. A 2000, 104, 2772-2779.

16. Xantheas, S.S. Anharmonic vibrational spectra of hydrogen bonded clusters: Comparison between higher energy derivative and mean-field grid based methods. Intern. Rev. Phys. Chem. 2006, 25, 719-733.

17. Roscioli, J.R.; Diken, E.G.; Johnson, M.A.; Horvath, S.; McCoy, A.B. Prying apart a water molecule with anionic H-bonding: A comparative spectroscopic study of the $\mathrm{X}-\mathrm{H}_{2} \mathrm{O}(\mathrm{X}=\mathrm{OH}, \mathrm{O}$, $\mathrm{F}, \mathrm{Cl}$, and $\mathrm{Br}$ ) binary complexes in the 600-3800 cm-1 region. J. Phys. Chem. A 2006, 110, 4943-4952. 
18. Ayotte, P.; Weddie, G.H.; Kim, J.; Johnson, M.A. Vibrational spectroscopy of the ionic hydrogen bond: Fermi resonances and ion-molecule stretching frequencies in the binary $\mathrm{X} \cdot \mathrm{H}_{2} \mathrm{O}(\mathrm{X}=\mathrm{Cl}$, $\mathrm{Br}$, I) complexes via argon predissociation spectroscopy. J. Am. Chem.Soc.1998, 120, 1236112362.

19. Barone, V. Anharmonic vibrational properties by a fully automated second-order perturbative approach. J. Chem. Phys. 2005, 122, art. no. 014108, 1-10.

20. Froyd, K.D.; Lovejoy E.R. Experimental thermodynamics of cluster ions composed of $\mathrm{H}_{2} \mathrm{SO}_{4}$ and $\mathrm{H}_{2}$ O. 1. Positive ions. J. Phys. Chem. A 2003, 107, 9800-9811.

21. Froyd, K.D.; Lovejoy E.R. Experimental thermodynamics of cluster ions composed of $\mathrm{H}_{2} \mathrm{SO}_{4}$ and $\mathrm{H}_{2}$ O. 2. Measurements and ab initio structures of negative ions. J. Phys. Chem. A 2003, 107, 9812-9824.

22. Sorokin, A.; Arnold, F.; Wiedner, D. Formation and growth of sulfuric acid-water cluster ions: Experiments, modelling, and implications for ion-induced aerosol formation Atmospheric Environment 2006, 40, 2030-2045.

23. Nadykto, A.B.; Yu, F.; Herb, J. Towards understanding the sign preference in binary atmospheric nucleation. Phys. Chem. Chem. Phys. 2008, 10, 7073-7078.

(C) 2009 by the authors; licensee Molecular Diversity Preservation International, Basel, Switzerland. This article is an open-access article distributed under the terms and conditions of the Creative Commons Attribution license (http://creativecommons.org/licenses/by/3.0/). 